\title{
Genetic Control of Dicumarol Levels in Man
}

\author{
Elliot S. Vesell and John G. Page \\ From the Section on Pharmarcogenetics, Laboratory of Chemical Pharmacology, \\ National Heart Institute, National Institutes of Health, \\ Bethesda, Maryland 20014
}

A в S T R A C T The mean half-life of dicumarol in the plasma of seven sets of identical and seven sets of fraternal twins after a single oral dose of 4 $\mathrm{mg} / \mathrm{kg}$ was $43.6 \pm \mathrm{SD} 17.9 \mathrm{hr}$. Half-lives ranged from 7 to $74 \mathrm{hr}$ in these 28 normal adults not receiving other drugs for $2 \mathrm{wk}$ preceding dicumarol administration. Large differences among unrelated individuals in dicumarol half-life disappeared almost completely in identical twins, but persisted to some extent in most sets of fraternal twins. These results indicate that marked differences among subjects in dicumarol half-life are under genetic rather than environmental control. Reproducibility of values for dicumarol half-life was demonstrated. A direct relationship between the dose and the half-life of dicumarol occurred in unrelated volunteers administered progressively larger doses at 10-day intervals. Dose dependence of the half-life of a drug results in increased variability of half-life and hence in greater risks of toxicity on long-term therapy. Risks of toxicity on the one hand and of failure to anticoagulate adequately on the other can be reduced by determining dicumarol half-life before starting long-term therapy. Half-lives for dicumarol and phenylbutazone tended to be correlated in the 28 twins, but no correlation occurred between dicumarol and antipyrine half-lives.

\section{INTRODUCTION}

Among certain patients receiving a standard dose of a drug, large differences in its metabolism may cause either toxicity or failure to achieve therapeutic benefit. Commonly employed drugs with large individual variations in rates of elimination

Received for publication 1 August 1968. from human plasma include antipyrine (1), dicumarol (2), dilantin (3), and phenylbutazone (4). Marked individual differences in drug metabolism might suggest that individual rates be ascertained before inaugurating long-term therapy. However, neither the mechanisms responsible for these individual differences nor confidence in the reproducibility of a subject's drug half-life have been sufficiently well established to suggest the procedure of determining drug half-lives before initiating long-term therapy. Additional considerations against the use of this procedure might appear to be that some drugs enhance their own metabolism (5), that several substances accelerate the metabolism of many pharmacologic agents (6) by nonspecifically increasing the activity of drug-metabolizing enzymes in liver microsomes and that the half-lives of a number of drugs, including dicumarol (3), dilantin, and phenylbutazone (7), vary with the dose and thereby fluctuate on longterm administration. In spite of these objections, the experiments presented below suggest certain advantages in determining individual rates of drug metabolism before beginning long-term therapy.

Recently we reported that significant differences among individuals in the metabolism of antipyrine (8) and phenylbutazone (9) were primarily under genetic rather than environmental control. These studies also demonstrated reproducibility in the rates at which antipyrine and phenylbutazone were eliminated from plasma of normal subjects not receiving other drugs. The predominant role of genetic factors in controlling individual differences in drug metabolism was not entirely expected. Studies in mice receiving a single hypnotic dose of hexobarbital showed that differences among animals were caused not only by genetic 
factors but also by multiple environmental conditions (10).

A previous study on the rate of metabolism of dicumarol in various families reported a sib-sib correlation without a parent-offspring correlation and attributed individual differences in dicumarol metabolism to the operation of recessive genes (11). In general, conclusions derived from sib-sib correlations in the absence of a parent-offspring correlation should be corroborated by studies based on other methods because, as emphasized by Roberts (12), the environment of young sibs is generally closer than that of parent and child. Thus environmental as well as genetic factors may contribute to such a result. The present experiments reveal that among individuals not receiving other drugs large differences in the plasma halflife of dicumarol are under genetic, rather than environmental, control. The half-life of dicumarol was observed to be a reproducible, stable trait.

\section{METHODS}

14 pairs of twins from the Washington, D. C., area volunteered for this study after reading a description of its objectives in the Washington Post. All subjects were 21 $\mathrm{yr}$ of age or over, Caucasian and in good health, as determined by history, physical examination, and routine laboratory studies. None took drugs for 2 wk before administration of dicumarol. Typing of the volunteers for approximately 30 blood groups helped establish the nature of the twinship and showed that seven sets of twins were identical and seven were fraternal. These results confirmed the twins' view of their relationship and the impression of the authors concerning their zygosity.

At 0830 each subject received a single oral dose of 4 $\mathrm{mg} / \mathrm{kg}$ of dicumarol (Bishydroxycoumarin, 3,3'-methylenebis [4-hydroxycoumarin]) in 25-mg tablets (Eli Lilly \& Co., Indianapolis, Ind.). Although abdominal discomfort occurred in approximately half the subjects, this dose was selected for several reasons. Rates of elimination of dicumarol depend on the dose (2) and greater individual variations occur at higher dosages (7). A dose of dicumarol of $4 \mathrm{mg} / \mathrm{kg}$ depresses prothrombin time, whereas a dose of $2 \mathrm{mg} / \mathrm{kg}$ does not (2). Since the purpose of this study is to determine the basis for individual variations in dicumarol metabolism at therapeutic doses, the former dose was selected. $24 \mathrm{hr}$ after administration of dicumarol, blood was drawn in tubes containing oxalate and within $12 \mathrm{hr}$ the plasma was assayed for dicumarol by the method of Axelrod, Cooper, and Brodie (13).

Plasma $(2.0 \mathrm{ml})$ was acidified by mixing with $0.5 \mathrm{ml}$ of $3 \mathrm{~N} \mathrm{HCl}$. After addition of water $(1.0 \mathrm{ml})$ the drug was extracted by shaking the acidified plasma for $30 \mathrm{~min}$ in $20 \mathrm{ml}$ of spectrally pure heptane from Fisher Scientific
Co., Pittsburgh, $\mathrm{Pa}$. The mixture was centrifuged for 5 $\mathrm{min}$ at $2000 \mathrm{~g}$. The heptane layer $(15 \mathrm{ml})$ was removed and mixed with $\mathrm{NaOH}(5 \mathrm{ml}$ of $2.5 \mathrm{~N}$ ). After shaking the mixture for $10 \mathrm{~min}$ and centrifuging it for $5 \mathrm{~min}$ at $2000 \mathrm{~g}$, we discarded the heptane layer and measured the optical density of the aqueous layer at $315 \mathrm{~m} \mu$ in a Beckman DU spectrophotometer. The blank, composed of $\mathrm{NaOH}(2.5 \mathrm{~N})$, was negligible. A standard curve was prepared by dissolving dicumarol (100 $\mathrm{mg}$ and lesser amounts) with $\mathrm{NaOH}(12.5 \mathrm{ml}$ of $0.1 \mathrm{~N})$.

Subsequent venipunctures were performed at intervals of 12 or sometimes $24 \mathrm{hr}$. To determine whether administration of a single dose of dicumarol altered rates of elimination of a subsequent dose, we gave four sets of twins a second similar dose of dicumarol 10 or more days after the first dose.

Although the half-life of dicumarol has been shown to be dose-dependent, the half-life is claimed not to be directly proportional to the dose (2). Weiner, Shapiro, Axelrod, Cooper, and Brodie (2) did not study blood levels at either $2 \mathrm{mg} / \mathrm{kg}$, the dose used by Motulsky (11), or at $4 \mathrm{mg} / \mathrm{kg}$, the dose used by us. To permit comparison of our results with those of Motulsky (11), we determined the half-lives of dicumarol in healthy subjects over $21 \mathrm{yr}$ of age after a dose of $2 \mathrm{mg} / \mathrm{kg}$ and 10 days later after a dose of $4 \mathrm{mg} / \mathrm{kg}$. Three of these subjects later received a dose of $6 \mathrm{mg} / \mathrm{kg}$ on each of 6 successive days, after which the half-life of dicumarol in plasma was determined. To minimize alterations in prothrombin time, a potent synthetic vitamin $\mathrm{K}$ analogue, mendione sodium diphosphate (Synkavite, Roche Products Ltd., London), was given orally in a dose of $5 \mathrm{mg}$ on each day of and for 10 days after dicumarol administration. Synkavite exerts no effect on the metabolism of dicumarol $(2,7)$. Prothrombin times were determined by the method of Quick (14) on days 5 and 6 of dicumarol administration and for 1 wk thereafter.

\section{RESULTS}

Fig. 1 shows the decay of dicumarol from the plasma of six representative sets of identical and fraternal twins after a single oral dose of $4 \mathrm{mg} / \mathrm{kg}$. As in other studies of dicumarol metabolism $(2,7$, $16)$, the lines were fitted by eye. Table I gives the half-life of dicumarol determined from such curves for each individual, as well as their previously published values for antipyrine (8) and dicumarol (9) half-lives, included here to permit calculation of correlations between the half-lives of these three drugs by the method of Bartlett (15). The contribution of heredity to the trait under study was estimated from the formula (17) : variance within pairs of fraternal twins minus variance within pairs of identical twins/variance within pairs of fraternal twins. This formula encompasses values from zero, indicating an insignificant hereditary 


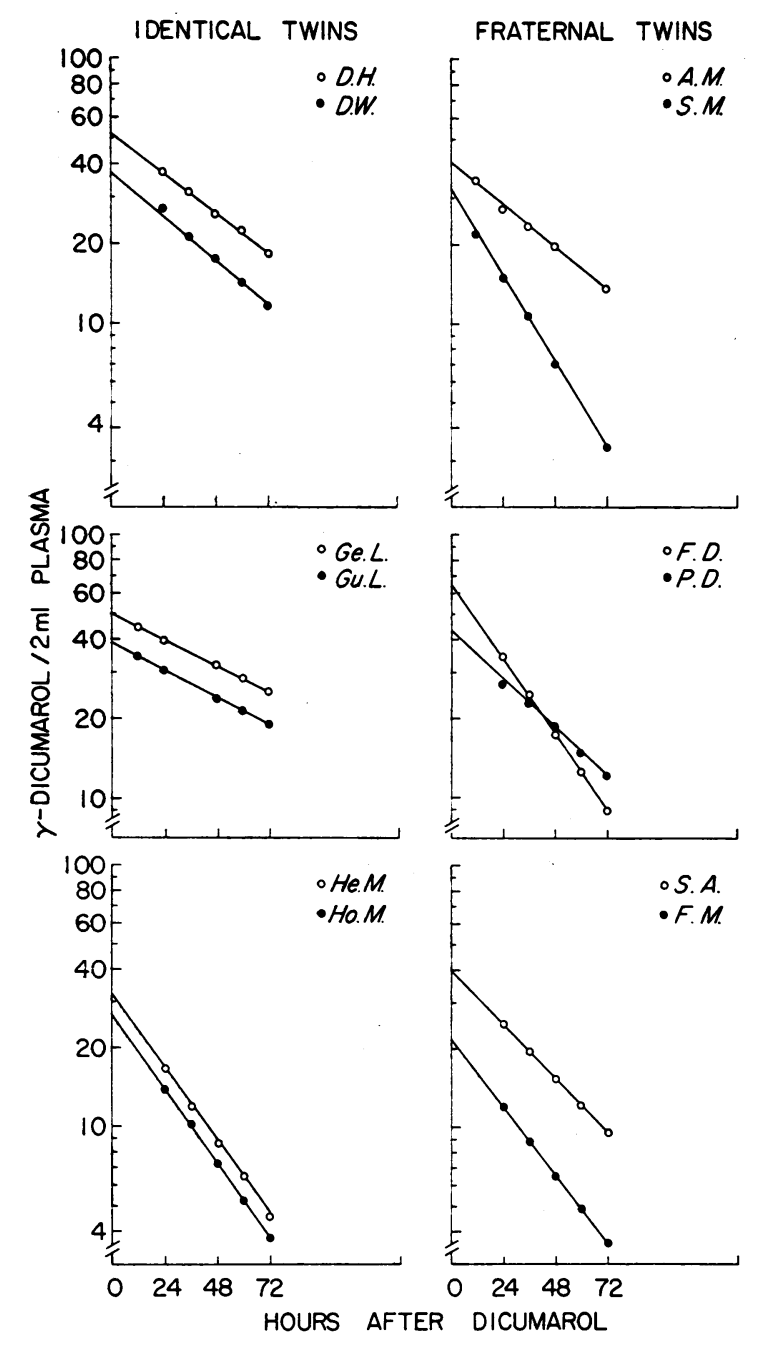

FIGURE 1 Decline of dicumarol in the plasma of three sets of identical twins (left) and three sets of fraternal twins (right). The log of the dicumarol concentration in $2 \mathrm{ml}$ of plasma is shown at intervals after a single oral dose $(4 \mathrm{mg} / \mathrm{kg})$.

component, to 1 , indicating a strong hereditary influence. Variance within pairs was calculated from the formula (17): $\Sigma$ (difference between twins) ${ }^{2} /$ $2 n$. The value of 0.97 for the contribution of heredity indicated that hereditary factors controlled the wide variations observed in the decay of dicumarol from plasma. The difference in intrapair variance between identical and fraternal twins was significant (see Table I). The intrapair correlation coefficient of 1.0 for identical twins and of 0.7 for fraternal twins strengthened the conclusion. For a trait that is genetically determined, a value of 0.5 might be anticipated in fraternal twins because they are identical with respect to approximately half the total number of genes, whereas in identical twins a value of 1.0 would be expected.

Since the sibs from five of the seven sets of identical twins lived apart, similarity in their dicumarol half-lives seemed not to be attributable to those environmental factors arising from cohabitation and consumption of identical food. Because heavy cigarette smoking with exposure to nicotine (18), 3,4-benzpyrene (5), methylcholanthrene (5), and coffee and tea ingestion with consumption of caffeine (19) have recently been associated with induction of certain enzymes, a history of some of these habits was taken in each twin. Table I reveals no clear correlation between these habits and the rate of dicumarol decay; in one set of identical twins with very similar dicumarol half-lives $D$. T. did not smoke, whereas U. W. had smoked two packs of cigarettes each day for several years. A similar lack of correlation appears also for coffee consumption.

The half-lives of dicumarol in the four sets of twins who received a second identical dose were within approximately $5 \%$ of the initial values ( $\mathrm{Ta}$ ble II). This confirms earlier observations (2) that the rate of decay of dicumarol is a stable trait.

The mean value with standard deviation for the half-life of dicumarol in the 28 twins receiving $4 \mathrm{mg} / \mathrm{kg}$ was $43.6 \pm 17.9 \mathrm{hr}$. No sex difference was observed; mean values for the 12 males and 16 females with standard deviation were $43.9 \pm$ 21.2 and $43.4 \pm 19.1 \mathrm{hr}$, respectively. There was a 10 -fold range in half-lives from 7 to $74 \mathrm{hr}$.

Table III shows that in five unrelated normal subjects the dicumarol half-life doubled when an oral dose of $2 \mathrm{mg} / \mathrm{kg}$ was followed 10 days later by a dose of $4 \mathrm{mg} / \mathrm{kg}$. In the three subjects who later received $2 \mathrm{mg} / \mathrm{kg}$ on each of 6 successive days, the half-life determined after the 6th day was approximately twice that observed after a single dose of $4 \mathrm{mg} / \mathrm{kg}$. On the 5 th and 6 th days of dicumarol administration, the drug levels were 42 , 39 , and $32 \mathrm{mg} / \mathrm{liter}$ and 59,56 , and $44 \mathrm{mg} / \mathrm{liter}$, respectively, in these three individuals. In spite of vitamin $\mathrm{K}$ administration the prothrombin times were prolonged to 30.7,14.9, and $19.0 \mathrm{sec}$ (control $11.7 \mathrm{sec}) 24 \mathrm{hr}$ after the fifth dose, and to 31.4 , 15.9, and $23.4 \mathrm{sec}$ (control $10.9 \mathrm{sec)} 24 \mathrm{hr}$ after the sixth dose. Therefore, dicumarol administration was discontinued and the half-life determined. 
TABLE I

Dicumarol, Antipyrine, and Phenylbutazone Half-Lives with Smoking and Coffee History in 28 Twins

\begin{tabular}{|c|c|c|c|c|c|c|}
\hline \multirow[b]{2}{*}{ Twin } & \multirow[b]{2}{*}{ Age, sex } & \multicolumn{3}{|c|}{ Half-life } & \multirow[b]{2}{*}{ Smoking } & \multirow[b]{2}{*}{ Coffee } \\
\hline & & Dicumarol & Antipyrine & Phenylbutazone & & \\
\hline & & $h r$ & $h r$ & days & $p a c k / d a y$ & cups/day \\
\hline \multicolumn{7}{|c|}{ Identical twins } \\
\hline Ho. M. & $48, \mathrm{M}$ & 25.0 & 11.3 & 1.9 & 0.5 & 2 \\
\hline Ho. M. & $48, M$ & 25.0 & 11.3 & 2.1 & 1 & 3 \\
\hline D. T. & $43, \mathrm{~F}$ & 55.5 & 10.3 & 2.8 & 0 & $5-6$ \\
\hline V.W. & $43, \mathrm{~F}$ & 55.5 & 9.6 & 2.9 & 2 & $8-10$ \\
\hline J. G. & $22, \mathrm{M}$ & 36.0 & 11.5 & 2.8 & 1 & $1-2$ \\
\hline P. G. & $22, \mathrm{M}$ & 34.0 & 11.5 & 2.8 & 1 & $1-2$ \\
\hline Ja. T. & $44, \mathrm{M}$ & 74.0 & 14.9 & 4.0 & 0 & 6 \\
\hline Ja. T. & $44, \mathrm{M}$ & 72.0 & 14.9 & 4.0 & 0 & $2-3$ \\
\hline C. J. & $55, \mathrm{~F}$ & 41.0 & 6.9 & 3.2 & 0 & 2 \\
\hline F. J. & $55, \mathrm{~F}$ & 42.5 & 7.1 & 2.9 & 0 & 2 \\
\hline Ge. L. & $45, \mathrm{M}$ & 72.0 & 12.3 & 3.9 & 0 & 4 \\
\hline Gu. L. & $45, \mathrm{M}$ & 69.0 & 12.8 & 4.1 & 0 & 4 \\
\hline D. H. & $26, \mathrm{~F}$ & 46.0 & 11.0 & 2.6 & 0 & $0-1$ \\
\hline D. W. & $26, \mathrm{~F}$ & 44.0 & 11.0 & 2.6 & 0 & $3-4$ \\
\hline \multicolumn{7}{|c|}{ Fraternal twins } \\
\hline A. M. & $21, \mathrm{~F}$ & 45.0 & 15.1 & 7.3 & 1.5 & 2 \\
\hline S. M. & $21, \mathrm{M}$ & 22.0 & 6.3 & 3.6 & 0 & 0 \\
\hline D. L. & $36, F$ & 46.5 & 7.2 & 2.3 & 0 & $2-3$ \\
\hline D. S. & $36, F$ & 51.0 & 15.0 & 3.3 & 2 & $3-4$ \\
\hline S. A. & $33, \mathrm{~F}$ & 34.5 & 5.1 & 2.1 & 1 & 2 \\
\hline F. M. & $33, F$ & 27.5 & 12.5 & 1.2 & 0.5 & 2 \\
\hline Ja. H. & $24, F$ & 7.0 & 12.0 & 2.6 & 0 & $10-15$ \\
\hline Je. H. & $24, F$ & 19.0 & 6.0 & 2.3 & 1.5 & 10 \\
\hline F. D. & $48, \mathrm{M}$ & 24.5 & 14.7 & 2.8 & 0 & 1 \\
\hline P. D. & $48, \mathrm{M}$ & 38.0 & 9.3 & 3.5 & 1.5 & 8 \\
\hline L. D. & $21, \mathrm{~F}$ & 67.0 & 8.2 & 2.9 & 1 & 6 \\
\hline L. W. & $21, F$ & 72.0 & 6.9 & 3.0 & 1 & $2-3$ \\
\hline E. K. & $31, F$ & 40.5 & 7.7 & 1.9 & 0 & 0 \\
\hline R. K. & $31, \mathrm{M}$ & 35.0 & 7.3 & 2.1 & 1 & 0 \\
\hline
\end{tabular}

The difference between identical and fraternal twins in intrapair variance is significant: $P<0.005\left(\mathrm{~F}=36.0, \mathrm{~N}_{1}=\mathrm{N}_{2}\right.$ $=7$ ).

TABLE II

Values of Half-Lives on Repeat Administration of Dicumarol ( $4 \mathrm{mg} / \mathrm{kg}$ )

\begin{tabular}{lrr} 
& \multicolumn{2}{c}{ Half-life } \\
\cline { 2 - 3 } Twin & Initial & Repeated \\
\hline & \multicolumn{2}{c}{$h r$} \\
D. H. & 46.0 & 45.0 \\
D. W. & 44.0 & 42.5 \\
Ge.L. & 72.0 & 75.5 \\
Gu. L. & 69.0 & 66.8 \\
Ja. T. & 74.0 & 70.8 \\
Jo. T. & 72.0 & 73.6 \\
Ja. H. & 7.0 & 7.5 \\
Je. H. & 19.0 & 18.4 \\
\hline
\end{tabular}

TABLE III

Relationship of Dicumarol Half-Life to Dose in Five Unrelated Normal Adults

\begin{tabular}{lllll}
\hline & & \multicolumn{3}{c}{ Half-life after dose of } \\
\cline { 3 - 5 } Volunteer & Age, sex & $\begin{array}{c}2 \mathrm{mg} / \\
\mathbf{k g}\end{array}$ & $\begin{array}{c}4 \mathrm{mg} / \\
\mathbf{k g}\end{array}$ & $\begin{array}{c}2 \mathrm{mg} / \mathrm{kg} \\
\text { daily } \\
\times 6\end{array}$ \\
& & & & \multicolumn{3}{c}{$\mathrm{hr}$} & \\
E. V. & $34, \mathrm{M}$ & 25.0 & 42.5 & 80 \\
J. P. & $27, \mathrm{M}$ & 24.6 & 41.0 & 84 \\
H. C. & $53, \mathrm{~F}$ & 30.5 & 68.0 & 144 \\
F. G. & $34, \mathrm{M}$ & 18.2 & 38.5 & \\
H. B. & $28, \mathrm{M}$ & 23.8 & 51.5 & \\
\hline
\end{tabular}

Mean half-life on $2 \mathrm{mg} / \mathrm{kg}$ dose $=24.4 \mathrm{hr}$; on $4 \mathrm{mg} / \mathrm{kg}$ dose $=48.3 \mathrm{hr}$. Ratio of half-lives on these two dosages $=0.505$. 


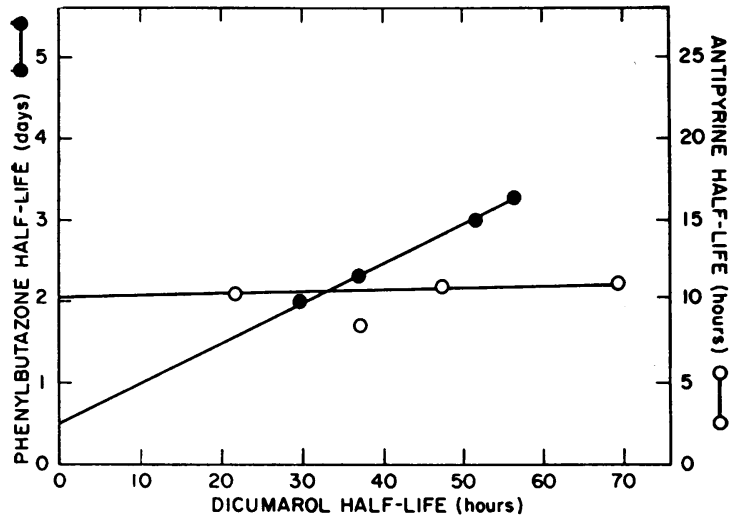

FIGURE 2 Relationship between half-lives of dicumarol and phenylbutazone and between half-lives of dicumarol and antipyrine in various individuals according to the method of Bartlett (15).

The prothrombin times returned to normal within 2 to 7 days after discontinuation of dicumarol.

Rates at which an individual metabolized dicumarol and phenylbutazone tended to be correlated, but no correlation between rates of dicumarol and antipyrine metabolism occurred (Fig. 2). These correlations were determined by the method of Bartlett (15).

\section{DISCUSSION}

These studies indicate that among healthy adults not receiving other drugs large differences in the metabolism of dicumarol arise from genetic rather than environmental factors. Previous reports had demonstrated the existence in man of marked but generally reproducible variations in dicumarol metabolism $(2,11)$. The family studies of Motulsky (11) revealed sib-sib correlations in corrected dicumarol half-life of $0.347 \pm 0.091$ without parentchild or midparent-midoffspring correlations. These data suggested that the rate of dicumarol decay was genetically determined and controlled by the operation of recessive genes (11). However, young sibs frequently share a more similar environment than parent and sib; therefore, sib-sib correlations should not be interpreted to indicate unequivocally genetic control of a trait because such correlations may arise from environmental as well as genetic causes.

The twin studies reported here indicate that the decay of dicumarol from plasma is a genetically determined trait. Only two of the seven sets of identical twins lived in the same household; there- fore, the close resemblance between identical twins in dicumarol half-life cannot be attributed to those environmental factors operating on individuals sharing the same home and meals. Since the metabolic fate of dicumarol in man has not been established, other than that dicumarol is not normally excreted unchanged either in urine or feces (2), and that $99 \%$ of a standard dose is bound to plasma proteins (2), the biochemical site of action of these genes is unknown.

Since large individual differences in the metabolism of the three drug that we have thus far investigated (dicumarol, antipyrine [8], and phenylbutazone [9] ) are primarily under genetic, rather than environmental, control, predominantly genetic control may also be exerted over wide individual variations in the metabolism of several other drugs. Such a possibility suggests that individual rates of metabolism of many drugs might be constant, reproducible traits, as appears true in these studies when a single dose is given to healthy adults not receiving other drugs.

A variety of environmental factors can alter drug metabolism (10). For dicumarol, these include the size of the dose $(2,7,16)$, the extent and rapidity of gastrointestinal absorption $(2,16)$, and prior ingestion of substances capable of inducing drugmetabolizing enzymes located in liver microsomes (7). The present studies confirmed the dose dependence of dicumarol half-life (2) but in the doses selected indicate that the dicumarol half-life varied directly with the dose, contrary to conclusions drawn from experiments conducted with other doses (2). The half-life was doubled after a dose of $4 \mathrm{mg} / \mathrm{kg}$ from that obtained after a 2 $\mathrm{mg} / \mathrm{kg}$ dose given 10 days previously. Also the mean dicumarol half-life in our 28 individuals administered a single oral dose of $4 \mathrm{mg} / \mathrm{kg}$ was 43.6 $\mathrm{hr}$, almost twice the value of $23.6 \mathrm{hr}$ reported in volunteers given in single oral dose of $2 \mathrm{mg} / \mathrm{kg}$ (11). Even after 5 days of a daily dose of $2 \mathrm{mg} /$ $\mathrm{kg}$, dicumarol continued to rise in the plasma of our two volunteers, though on purely kinetic considerations for drugs whose half-life is independent of dose the plasma level should have reached $90 \%$ of the equilibrium value by the 4 th day. ${ }^{1}$ Despite

\footnotetext{
1 This was calculated from the formula $C_{n} / C_{\infty}=1-$ $e^{-k n \Delta t}$ which is derived by dividing the formula $C_{n}=$ $C_{0}\left(1-e^{-k n \Delta t}\right) / \mathrm{Fr}$ by $C_{\infty}=C_{0} / \mathrm{Fr}$. In this formula $C_{0}=$ dose $(\mathrm{mg}) /$ volume of distribution; $\Delta t=$ dosage interval;
} 
intensive investigation, the explanation for dose dependence of plasma half-life remains obscure. Weiner et al. (2) attributed it to saturation of the biochemical mechanism that metabolized the drug. Dayton, Cucinell, Weiss, and Perel (7), employing quantitative thin-layer chromatography of dog plasma to insure specificity of the assay procedure for dicumarol (14) and to eliminate the possibility of interfering metabolites, concluded that it is "a special case of inhibition, the self-inhibition of metabolism of a drug." They postulated the existence of loose and firm types of binding between drug and enzyme and suggested that the more tightly bound drug-enzyme complexes are formed with a high dose of drug, resulting in a more prolonged decrease in enzyme activity than occurs with the loose binding of low dosages (7).

The present studies confirmed variations among individuals in gastrointestinal absorption of dicumarol, first investigated by Weiner et al. (2) and later by others (16). For several days after a high oral dose, little decline of plasma dicumarol occurred in certain individuals, a phenomenon best explained by continued absorption of drug from the gastrointestinal tract during this period.

Various drugs, including phenobarbital, induce hepatic microsomal drug-metabolizing enzymes and shorten the plasma half-life of dicumarol (7). Our twins did not receive such drugs for at least 2 wk before dicumarol administration, so that their plasma half-lives probably represent basal, uninduced values. This conclusion is supported by results obtained in four sets of twins whose halflives, redetermined after a second identical dose of $4 \mathrm{mg} / \mathrm{kg}$, were close to initial values (Table II). However, several substances such as 3,4benzpyrene (5), 3-methylcholanthrene (5), nicotine (18), and caffeine (19), to which many individuals expose themselves, can also accelerate drug metabolism. Therefore, a history of cigarette smoking and coffee ingestion was recorded in the 28 twins (Table I). No correlation with the rate of dicumarol metabolism was detected; in a set of identical twins with closely similar dicumarol halflives, one individual did not smoke, whereas the other consumed two packs a day. Similar dis$\bar{C}_{n}$ and $C_{\infty}=$ plasma levels at the beginning of $n$ dosage intervals and as $n$ approaches infinite dosage intervals respectively; $k=$ elimination constant; $\mathrm{Fr}=$ fraction eliminated during the dosage interval. cordant examples occurred for both smoking and coffee consumption. However, further work is required to establish whether a relationship exists between these agents and levels of drug metabolizing enzymes in humans.

The present study suggests that the rate of dicumarol metabolism in an individual tends to correlate with his rate of phenylbutazone metabolism, but not with his rate of antipyrine metabolism (Fig. 2). Previously we reported that individuals showed no correlation in their rates of phenylbutazone and antipyrine metabolism (8). Even though these drugs are congeners, they are hydroxylated at different positions $(4,1)$, a fact which suggests that these drugs are metabolized by two functionally distinct enzymes. In this and previous studies $(1,2,4-9)$ it is assumed that the half-lives of antipyrine, phenylbutazone, and dicumarol reflect the activity of certain hepatic microsomal enzymes responsible for drug metabolism. However, the tendency toward correlation between rates of dicumarol and phenylbutazone metabolism in an individual may be related to the fact that both drugs are bound avidly and almost completely to plasma proteins. Alternatively, both drugs may be degraded by similar enzymatic steps. Whatever the explanation, the existence of such a correlation raises the possibility that within an individual the rates of metabolism of other drugs seemingly unrelated in chemical structure may also be correlated. Such a possibility further suggests the value of determining rates at which individual patients metabolize a few representative drugs so that their therapeutic responsiveness to these may be maximized, thereby avoiding toxicity on the one hand and undertreatment on the other. Reproducibility of an individual's rates of metabolism of dicumarol, antipyrine (8), and phenylbutazone (9) also indicates the soundness of such a procedure.

The dose dependence of dicumarol and phenylbutazone half-lives might be interpreted to argue against determining individual rates of drug metabolism before chronic administration. Plasma half-lives of such drugs should be measured precisely because those patients in whom the drugs are slowly metabolized will be rendered particularly liable to toxicity on chronic therapy. For example, the plasma half-lives of dicumarol observed in the present study ranged from 7 to 74 
hr. On long-term dosage the blood level in the individual who metabolizes the drug with a halflife of $7 \mathrm{hr}$ will not change appreciably if dicumarol is given every $24 \mathrm{hr}$, and hence the half-life of the drug will remain at $7 \mathrm{hr}$. In contrast blood concentrations of dicumarol in the individual who metabolizes the drug with an initial half-life of $74 \mathrm{hr}$ will rapidly increase on chronic administration, and the half-life will lengthen. Increased dicumarol half-life in turn leads to further increases in the plasma level of drug. Therefore, even with drugs whose half-lives are dose-dependent, determination of the plasma half-life after a single dose is advisable. Prothrombin times, commonly employed to gauge response to anticoagulants and to adjust their dosage, have the disadvantage that the maximum prothrombinopenic effect occurs several days after dicumarol administration and thus the toxic effects may not be detected until several subsequent doses of the drug have been given (2).

Demonstration of the genetic control of individual variations in dicumarol and phenylbutazone metabolism and of increased danger of toxicity with slower drug metabolizers raises the possibility that high drug-metabolizing activity may have conferred certain advantages during evolution. Such an advantage would operate in environments where individuals chronically ingest as food or drugs appreciable amounts of those alkaloids whose metabolism may be dose-dependent and whose accumulation in high levels within the body is toxic. Thus, natural selection in certain environmental circumstances may have favored and may continue to favor individuals with high levels of drug-metabolizing enzymes.

\section{REFERENCES}

1. Brodie, B. B., and J. Axelrod. 1950. The fate of antipyrine in man. J. Pharmacol. Exptl. Therap. 98: 97.

2. Weiner, M., S. Shapiro, J. Axelrod, J. R. Cooper, and B. B. Brodie. 1950. The physiological disposition of dicumarol in man. J. Pharmacol. Exptl. Therap. 99: 409.
3. Kutt, H., W. Winters, R. Kokenge, and F. McDowell. 1964. Diphenylhydantoin metabolism, blood levels, and toxicity. Arch. Neurol. 11: 642 .

4. Burns, J. J., R. K. Rose, T. Chenkin, A. Goldman, A. Schulert, and B. B. Brodie. 1953. The physiological disposition of phenylbutazone (butazolidin) in man and a method for its estimation in biological material. J. Pharmacol. Exptl. Therap. 109: 346.

5. Conney, A. H. 1967. Pharmacological implications of microsomal enzyme induction. Pharmacol. Rev. 19: 317.

6. Cucinell, S. A., A. H. Conney, M. Sansur, and J. J. Burns. 1965. Drug interactions in man. I. Lowering effect of phenobarbital on plasma levels of bishydroxycoumarin (dicumarol) and diphenylhydantoin (dilantin). Clin. Pharmacol. Therap. 6: 420.

7. Dayton, P. G., S. A. Cucinell, M. Weiss, and J. M. Perel. 1967. Dose-dependence of drug plasma level decline in dogs. J. Pharmacol. Exptl. Therap. 158: 305.

8. Vesell, E. S., and J. G. Page. 1968. Genetic control of drug levels in man: antipyrine. Science. 161: 72.

9. Vesell, E. S., and J. G. Page. 1968. Genetic control of drug levels in man: phenylbutazone. Science. 159: 1479.

10. Vesell, E. S. 1968. Factors altering the responsiveness of mice to hexobarbital. Pharmacology. 1: 181.

11. Motulsky, A. G. 1964. Pharmacogenetics. Prog. Med. Genet. 3: 49.

12. Roberts, J. A. F. 1964 Multifactorial inheritance and human disease. Prog. Med. Genet. 3: 178.

13. Axelrod, J., J. R. Cooper, and B. B. Brodie. 1949. Estimation of dicumarol, 3,3'-methylenebis (4-hydroxycoumarin) in biological fluids. Proc. Soc. Exptl. Biol. Med. 70: 693.

14. Quick, A. J. 1957. Hemorrhagic Diseases. Lea \& Febiger, Philadelphia. 379.

15. Bartlett, M. S. 1949. Fitting a straight line when both variables are subject to error. Biometrics. 5: 207.

16. O'Reilly, R. A., P. M. Aggeler, and J. O. Gibbs. 1962. Hemorrhagic state due to surreptitious ingestion of bishydroxycoumarin. A detailed case study. New Engl. J. Med. 267: 19.

17. Osborne; R. H., and F. V. De George. 1959. Genetic Basis of Morphological Variation, An Evaluation and Application of the Twin Study Method. Harvard University Press. Cambridge. 17, 60.

18. Wenzel, D. G., and L. L. Broadie. 1966. Stimulatory effect of nicotine on the metabolism of meprobamate. Toxicol. Appl. Pharmacol. 8: 455.

19. Mitoma, C., T. J. Sorich, II, and S. E. Neubauer. 1968. The effect of caffeine on drug metabolism. Life Sci. 7: 145 . 